\title{
Suicide in Medical Doctors: A Review from Mainland China, 2008-2016
}

\author{
Hui Min Jin', Li Li Guo
}

\begin{abstract}
The purpose of this review is to summarize cases of Chinese doctors who have committed suicides between years 2008 and 2016. Moreover, we would like to appeal to the government and the public to increase their efforts to reduce death among Chinese doctors. We have reviewed public reports from local media, medical websites, official documents, and articles published in PubMed, Google Scholar, China National Knowledge Infrastructure (CNKI), and www.dxy.cn (a popular medical web in China) between years 2008 and 2016. Identified articles were published in either English or Chinese. A total of 51 cases (16 females and 35 males) of doctor suicides were reported or published between 2008 and 2016. Most incidents of death occurred between 20-59-year-olds, with a higher number observed within the 30-39 age group. Notably, the Jiangsu province had the highest number of reported doctor suicides ( 9 cases). Furthermore, detailed analysis revealed that the department of pediatrics ( $18 \%$, 9/51) topped the number of suicidal rates when compared to the other hospital units. Suicides occurred more often in the full-service, tertiary hospitals, accounting for $63 \%$ (32/51) of the reports. Jumping from a building was the most common way of death recorded, accounting for $55 \%$ (28/51) of total cases. Suicide is not just a medical issue but also a social concern. A key to reducing deaths by suicide in Chinese doctors should be a commitment of both the Chinese government and medical organizations to establish and implement a coordinated plan of action.
\end{abstract}

\section{Keywords}

Doctor suicide; Physician suicide; Overwork; Depression

\section{Introduction}

Due tolong-term exposure to high levels of occupational stress, medical doctors are vulnerable to the onset and development of some psychiatric disorders (such as anxiety, depression, and burnout syndrome), which trigger them to have increased suicidal ideation and attempts [13]. Recently, several studies have demonstrated medical doctors seem to have a relatively elevated risk for suicide. For example, Hawton et al. reported that the annual suicide rate was 18.8 per 100,000 for female doctors of England and Wales. The standard mortality rate for deaths by suicide was respectively 201.8 and 66.8 for female and male doctors, as compared with the matched general population [4]. Subsequently, Hawton et al. further reported 1.87 and 2.10 relative risks for suicide in physicians and dentists compared to 1.25 in the general population using data from the national registers for Denmark [5]. Petersen et al. also found an elevated suicide rate for white female physicians (standardized death rate ratio $=2.39,95 \% \mathrm{CI}=1.52-3.77$ ) compared to the working US population, but not dentists [6]. In a meta-analysis, the aggregate suicide rate ratio was estimated to be 1.41 [95\% confidence interval

Division of Nephrology, Shanghai Pudong Hospital, Fudan University, Pudong Medical Center, 2800 Gong Wei Road, Hemodialysis Center, Bao Shan Branch of No.1 People's Hospital, Shanghai Jiao Tong University, Shanghai, China

${ }^{\dagger}$ Author for correspondence: Hui Min Jin, Division of Nephrology, Shanghai Pudong Hospital, Fudan University, Pudong Medical Center, 2800 Gong Wei Road, Hemodialysis Center, Bao Shan Branch of No.1 People's Hospital, Shanghai Jiao Tong University Shanghai, China, email: hmjgli@163.com 
(CI), 1.21 - 1.65] for male, while 2.27 (95\% CI, 1.90 - 2.73) for female physicians, compared to the general population [7]. However, studies regarding suicide of medical doctors remain rare and suicide rates vary between countries.

China is one of the countries with highest burden of suicide in the word, with an estimated mean national suicide rate of 9.8 per 100,000 people in 2011 [8]. In addition to overwork [9], frequent medical violence against doctors due to "YI NAO"(an unique Chinese term that means the gangs or individuals who get paid to create medical and hospital disturbances) is one of important factors to lead to poor mental status of Chinese doctors and cause the tragedy $[2,10,11]$. Hereby, the suicide rate of Chinese doctors may be also higher than other countries, nevertheless, which has not been confirmed previously owing to the lacking of public information.

Recently, a lot of deaths in Chinese doctors have been reported as social media tools become a mainstream. The purpose of this study was to a) preliminarily summarize the suicide events in Chinese doctors from 2008 (when the Internet is starting to become widely used) to 2016; b) describe their characteristics to explore potential risk factors; and c) call for action to prevent more suicides from happening.

\section{Methods}

A systematic search of public reports on local media, medical websites, official documents, and articles published in PubMed, Google Scholar, China National Knowledge Infrastructure (CNKI), and www.dxy.cn (a popular medical web in China) between January 2008 and December 2016, was conducted by using keywords: 'doctor suicide,' and 'physician suicide.' In addition, reference lists of retrieved articles were also reviewed to manually find other potentially relevant articles. Articles were published in either English or Chinese. Suicides with relatively complete data description, including age, gender, specific hospital, departments and professional title were screened and included by two reviewers independently.

The doctor suicide rate was stratified according to different demographic variables. All data were expressed as number and percentage. Graphical data were generated usingeither Microsoft Excel or GraphPad Prism (GraphPad Software, La Jolla, CA, USA).

\section{Results}

From 2008 to 2016, 51 cases of doctor suicide (49 who died and 2 who were saved) occurred in China, of which seven were reported in 2008, four in 2009, seven in 2010, three in 2011, six in 2012, nine in 2013, five in 2014, five in 2015, and five in 2016 (Figure 1).

The demographics of these cases are summarized in Table 1. The proportion of male suicides was found to be more than twice higher when compared to females $(69 \%, 35 / 51$ vs $31 \%, 16 / 51)$ (Figure 2A). Most cases ended their lives at age between 20 and 59 years old, with the highest incidence rate observed in the age group of 30- 39 years old and then 40 - 49years old (Figure 2B). Region analysis showed that the doctor suicide was most prevalent in Jiangsu province (18\%, 9/51), followed by Sichuan (14\%, 7/51), Beijing $(8 \%, 4 / 51)$, and Shanghai $(8 \%, 4 / 51)$ (Figure 2C). Doctor suicide was reported to be involved in various departments, including Pediatrics, Emergency, Anesthesiology, General Surgery, Nephrology, Neurology, and others. Of them, the highest occurrence rate of doctor suicide was found in the department of pediatrics $(18 \%$, 9/51). This was followed by the department of emergency $(12 \%, 6 / 51)$ and anesthesiology $(8 \%$, 4/51) (Figure 2D). Jumping from a building was the most main method for suicide $(55 \%$, 28/51) and then the self-hanging $(12 \%, 6 / 51)$ (Figure 2E). Hospital disputes occurred more often in full-service, tertiary hospitals (63\%, $32 / 51$ ), approximately three times more than that taking place in secondary hospitals $(23 \%$, 12/51). Special hospitals $(10 \%, 5 / 51)$ and primary care facilities $(4 \%, 2 / 51)$ and had even fewer incidents (Figure 2F). Attending physician $(35 \%, 18 / 51)$, chief physician $(24 \%, 12 / 51)$, and associate chief physician $(20 \%, 10 / 51)$ were three main populations who had committed suicide (Figure 2G).

\section{Discussion}

Several studies have been performed on the issue of suicide of medical doctors in various countries $[3,4,12,13]$, but research for mainland China has not been reported. In this review, we, for the first time, summarize 51 suicide events in Chinese doctors from 2008 to 2016. Our findings suggest that the suicide rate was particularly high in doctors with male sex, age in the 30 - 49 years, service in the department of pediatrics of large hospitals (secondary and tertiary hospitals) and high professional title. Jumping from the high 


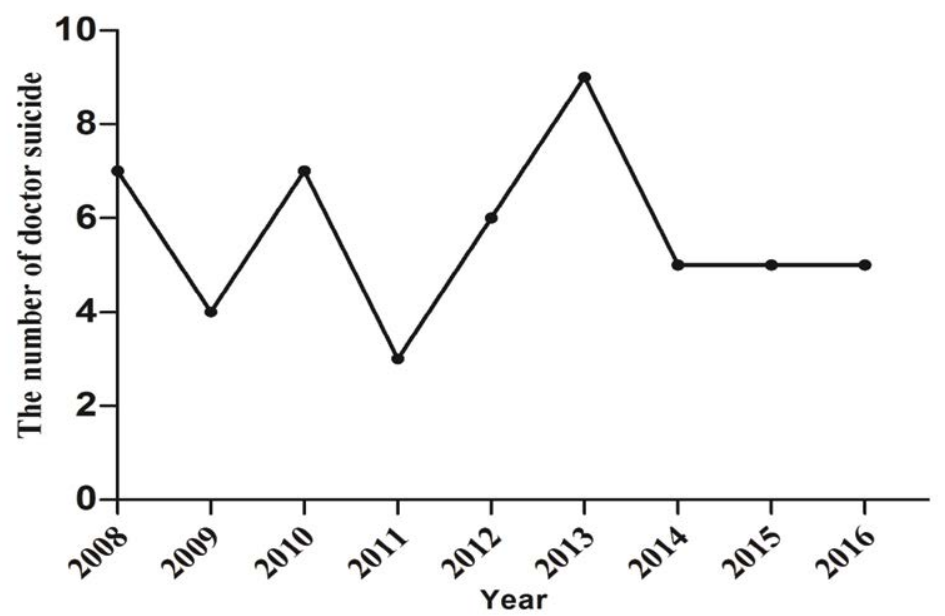

Figure 1: Yearly number of doctor suicide events in China from 2008 to 2016.

\begin{tabular}{|c|c|c|c|c|c|c|c|c|}
\hline Year & Name & Age & Gender & Professional title & Province & Hospital level & Department & Suicidal way \\
\hline 2016 & $\mathrm{Gu}^{*}$ & 25 & female & Medicine residents & Shanghai & Tertiary hospital & Internal Medicine & Jumping from a building \\
\hline 2016 & $\operatorname{Liu}^{* *}$ & 46 & male & Associate chief physician & Shanghai & Tertiary hospital & Orthopedics & Jumping from a building \\
\hline 2016 & Deng ${ }^{* *}$ & 31 & male & Attending physician & Hubei & Tertiary hospital & E.N.T & Jumping from a building \\
\hline 2016 & Shi** & 65 & male & Chief physician & Sichuan & Tertiary hospital & Cardiothoracic Surgery & Jumping from a building \\
\hline 2016 & Chen $^{* *}$ & 36 & male & Attending physician & Xian & Primary care facility & Pharmacy & Self-hanging \\
\hline 2015 & Zhou $^{* *}$ & 51 & male & Chief physician & Sichuan & Tertiary hospital & General Surgery & Self-hanging \\
\hline 2015 & Qian* & 39 & male & Attending physician & Liaoning & Tertiary hospital & General Surgery & Self-hanging \\
\hline 2015 & Ren* $^{*}$ & 37 & female & Attending physician & Jiangsu & Tertiary hospital & Pharmacy & Jumping into river \\
\hline 2015 & Zheng ${ }^{* *}$ & 43 & male & Attending physician & Gansu & Primary care facility & Pharmacy & Jumping into river \\
\hline 2015 & Chou** & 45 & male & Associate chief physician & Jiangsu & Tertiary hospital & Radiotherapy & Jumping from a building \\
\hline 2014 & Liu* $^{*}$ & 45 & female & Associate chief physician & Jiangsu & Tertiary hospital & Nephrology & Jumping from a building \\
\hline 2014 & $\operatorname{Lan}^{* *}$ & 51 & male & Chief physician & Fujian & Secondary hospital & Pediatrics & Jumping from a building \\
\hline 2014 & Dai** & 47 & male & Associate chief physician & Fujian & Tertiary hospital & Respiratory Medicine & Jump into river \\
\hline 2014 & Zhang** & 48 & male & Associate chief physician & Shanghai & Tertiary hospital & Urology & Jumping from a building \\
\hline 2014 & Jiang** & 24 & male & Medicine residents & Jiangsu & Tertiary hospital & Emergency & Unknown \\
\hline 2013 & Wang* & 33 & female & Attending physician & Hebei & Secondary hospital & Pediatrics & Jumping from a building \\
\hline 2013 & $\mathrm{Fu}^{* *}$ & 28 & female & Medicine residents & Hunan & Secondary hospital & Pediatrics & Jumping from a building \\
\hline 2013 & $\mathrm{Lu}^{*}$ & 25 & male & Medicine residents & Guangdong & Secondary hospital & Anesthesiology & Narcotic \\
\hline 2013 & $\mathrm{Gao}^{*}$ & 38 & male & Attending physician & Jilin & Tertiary hospital & Endocrinology & Jumping from a building \\
\hline 2013 & $\mathrm{Du}^{* *}$ & 36 & female & Attending physician & Jilin & Tertiary hospital & Neurology & Jumping from a building \\
\hline 2013 & $\mathrm{Du}^{* *}$ & 46 & male & Associate chief physician & Zhejiang & Secondary hospital & Pediatrics & Jumping from a building \\
\hline 2013 & Sun* & 35 & female & Attending physician & Hebei & Tertiary hospital & Pediatrics & Jumping from a building \\
\hline 2013 & Yang* & 39 & male & Attending physician & Anhui & Secondary hospital & Emergency & Jumping from a building \\
\hline 2013 & Huang** & 23 & female & Medicine residents & Anhui & Secondary hospital & Internal Medicine & Jumping from a building \\
\hline 2012 & $\operatorname{Jin}^{*}$ & 50 & male & Chief physician & Jiangsu & Tertiary hospital & Cardiology & Unknown \\
\hline 2012 & $\mathrm{Li}^{* *}$ & 28 & male & Assistant anesthesiologist & Hong Kong & Specific hospital & Anesthesiology & Narcotic \\
\hline 2012 & Huang** & 34 & male & Attending physician & Hong Kong & Specific hospital & General Surgery & Jumping from a building \\
\hline 2012 & $\mathrm{Li}^{*}$ & 48 & female & Associate chief physician & Sichuan & Tertiary hospital & $\begin{array}{l}\text { Obstetrics and } \\
\text { Gynecology }\end{array}$ & Pesticide \\
\hline 2012 & Xiao* & 48 & female & chief physician & Sichuan & Tertiary hospital & Digestive Medicine & Pesticide \\
\hline 2012 & Zhang* & 28 & female & Medicine residents & Henan & Secondary hospital & Pediatrics & Digoxin(700 tables) \\
\hline 2011 & $\mathrm{Li}^{*}$ & 42 & male & Associate chief physician & Beijing & Tertiary hospital & Neurology & Self-hanging \\
\hline 2011 & $W u^{* *}$ & 30 & male & Attending physician & Jiangsu & Specific hospital & Hand Surgery & Jumping from a building \\
\hline 2011 & Huang** & 49 & male & chief physician & Zhejiang & Secondary hospital & Emergency & Self-hanging \\
\hline 2010 & $\mathrm{Li}^{*}$ & 80 & male & chief physician & Jiangsu & Tertiary hospital & Nephrology & Jumping from a building \\
\hline 2010 & Huo** & 33 & male & Attending physician & Beijing & Specific hospital & General Surgery & Unknown \\
\hline
\end{tabular}


Review Hui Min Jin

\begin{tabular}{|c|c|c|c|c|c|c|c|c|}
\hline 2010 & $\mathrm{Li}^{* *}$ & 30 & female & Attending physician & Hubei & Specific hospital & $\begin{array}{l}\text { Obstetrics and } \\
\text { Gynecology }\end{array}$ & Jumping from a building \\
\hline 2010 & Yang ${ }^{* *}$ & 38 & male & Attending physician & Beijing & Tertiary hospital & Respiratory Medicine & Jumping from a building \\
\hline 2010 & $\mathrm{Gao}^{*}$ & 34 & male & Attending physician & Chongqing & Tertiary hospital & Ophthalmology & Unknown \\
\hline 2010 & $\mathrm{Ma}^{* *}$ & 50 & male & Chief physician & Xian & Tertiary hospital & Pediatrics & Jumping from a building \\
\hline 2010 & Wang* & 45 & female & Chief physician & Chongqing & Tertiary hospital & Neurology & Unknown \\
\hline 2009 & Zhao** & 35 & male & Attending physician & Beijing & Tertiary hospital & Emergency & Jumping from a building \\
\hline 2009 & $\mathrm{Mao}^{* *}$ & 44 & male & Associate chief physician & Jiangsu & Tertiary hospital & Pediatrics & Unknown \\
\hline 2009 & Jiang ${ }^{* *}$ & 50 & female & Chief physician & Hubei & Tertiary hospital & Dermatology & Wrist cutting \\
\hline 2009 & Wang ${ }^{* *}$ & 47 & male & Associate chief physician & Henan & Secondary hospital & Emergency & Hang oneself \\
\hline 2008 & Liang* & 24 & female & Assistant doctor & Sichuan & Tertiary hospital & Internal Medicine & Pesticide(paraquat) \\
\hline 2008 & $X u^{* *}$ & 34 & female & Doctorate student & Guangdong & Tertiary hospital & Internal Medicine & Jumping from a building \\
\hline 2008 & $\mathrm{Gao}^{* *}$ & 50 & male & Chief physician & Hubei & Secondary hospital & Emergency & Potassiumcyanide \\
\hline 2008 & Liu* $^{*}$ & 37 & male & Attending physician & Jiangsu & Secondary hospital & Pediatrics & Jumping from a building \\
\hline 2008 & Feng** & 25 & male & Medicine residents & Sichuan & Tertiary hospital & Anesthesiology & Jumping from a building \\
\hline 2008 & $\mathrm{Li}^{*}$ & 39 & male & Anesthesiologist & Sichuan & Tertiary hospital & Anesthesiology & Narcotic \\
\hline 2008 & $\mathrm{Li}^{* *}$ & 44 & male & Chief physician & Shanghai & Tertiary hospital & Nephrology & Jumping from a building \\
\hline
\end{tabular}

A

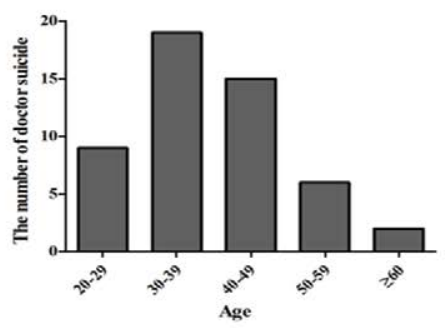

C

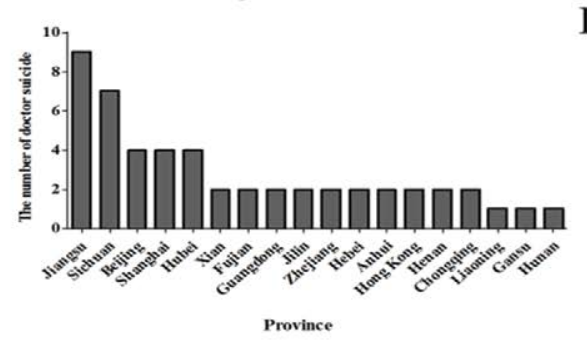

E

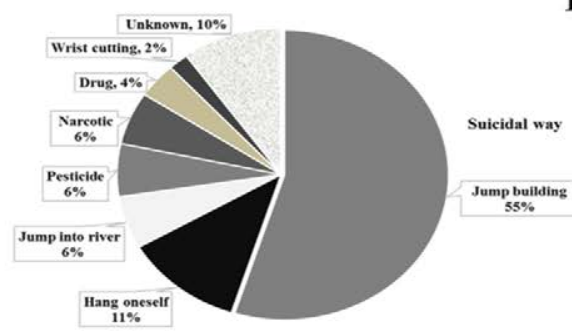

G

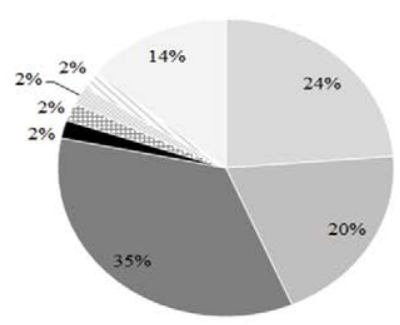

B

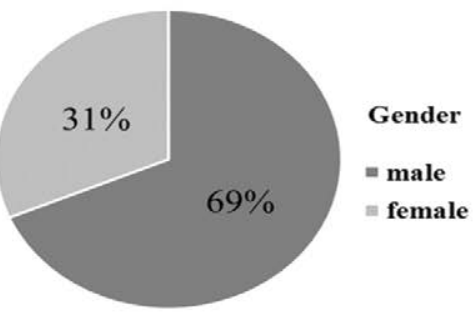

D

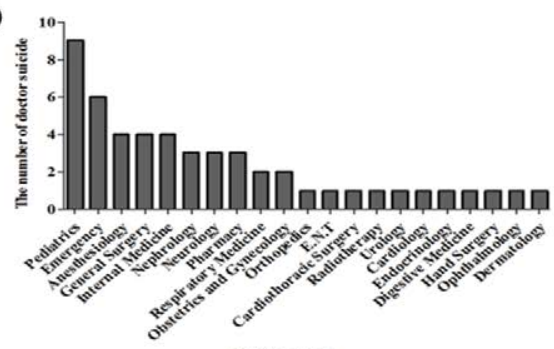

F

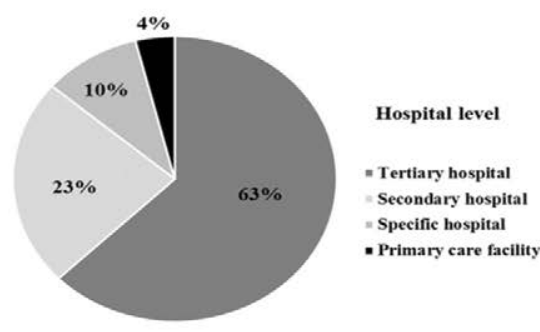

Professional title

Chief physician

- Associate chief physician

- A ttending physician

- Assistant doctor

HAssistant anesthesiologist

Anesthesiologist

Doctorate student

Medicine residents

Figure 2: Distribution of demographic characteristics for doctors who committed suicide in China from 2008 to 2016.

A, gender; $B$, age; C, province; D, departments; $E$, suicide methods; $F$, hospital level; $G$, professional title. 
building is the main suicide method for these doctors. Our results seemed to be in line with some of previous studies as following:

It is previously believed that more stress may be present in the female doctors due to their in escapable responsibilities for housework, children, and elderly care. Combining with the high workload, they may be very exhausting and possibly have more suicidal ideation than the male [14]. However, recent studies indicate the number of the suicide events in male doctors was obviously higher than the female population [4,15-17]. This finding may be potentially explained by the following fact that: 1) the proportion of male doctors is commonly higher than the female in the hospital; 2) the financial pressure is relatively larger for the male doctor because many doctors earn as little as 5,000 yuan RMB (US \$780) or less per month, and senior doctors' consultation fees are just 7 yuan RMB (\$1.14)[11], which is insufficient to support their family, or even lead to several male doctors being single. Unmarried status is another important risk factor for suicide owing to lack of comfort from a family when they encounter work related problems. It is reported that the relative risk of suicide for a single male physician is accordingly 15.5 times higher than for a married/cohabitant female physician [15].

Committing suicide was the highest in the age group of 30- 39 years old, which was also in accordance with the study of Hawton et al. [4]. Physicians in this age group might undergo a lot of work stress because they usually graduate the higher education and are early in career path. This speculation can be indirectly demonstrated by our previous study on Karoshi, in which we also found most cases of Karoshi occurred in doctors aged $30-59$ years, especially in those aged 30 - 39 years [9].

Since physicians have the knowledge and accessibility to lethal drugs, self-poisoning is suggested as the most common suicidal model for physicians $[15,16]$. However, in our study, only few doctors used this method. Hanging/ suffocation and jumping from heights were other leading suicide methods by doctors as described previously [12], which was also proved in our study.

The high suicide rate in doctors served in the large hospitals (secondary and tertiary hospitals) and with high professional title may be attributed to overwork and medical violence
Patient trust is low for clinics and community health centers, and they often seek care in larger hospitals, which leads to overwork in most doctors [10]. You can regularly hear complaints from doctors: 'I am swamped and tired, no time to get rest, no time to spend with families, no time to take care of the children. 'According to a report from the Ministry of Health, Labor and Welfare (MHLW) of Japan, Japanese physicians reportedly worked 66.4 hours on average per week in 2005; this work-hour is much longer than in European countries [18]. In public hospitals in Shenzhen of southern China, it is also reported that working lengthy was more than 60 hours a week in most doctors [2]. In addition, doctors' tasks have become more complex and risky due to the introduction of new diagnostic and treatment methods. Also, patients' demands and the number of law suits associated with medical accidents have increased. All these further added the stress to doctors [19].

Patients' high expectations and patient-doctor distrust often lead to the occurrence of medical violence [10], which may cause mental illness for doctors, such as anxiety and depression [2]. Only a few doctors with symptoms seek medical help [20], but these who cannot bear this stress may opt to commit suicide. The negative act of gatekeepers is also responsible for high physician suicide rate. The US Air Force (USAF) identified suicide as a department-wide problem in the early 1990s [5]. The program identified leaders (supervisors in all units) who serve as gatekeepers to oversee the risky individuals. In China, supervisors in the health system do little to help. They cannot stop impacts from patients and their families, and they have no law enforcement power. 'My love goes forever to my wife, and apologies to my colleagues' wrote by Dr. Zhou before he hung himself. Dr. Zhou was a dedicated liver surgeon working in Sichuan Province Hospital. Due to poor wound healing in a 60-year-old woman who suffered from complex gallstones, the patient and her family frequently went to the hospital to create noise, and disturb Dr. Zhou's work flow. After continuous entanglement, Dr. Zhou lost his patience, felt sleepless and burnout. One morning, Dr. Zhou committed suicide, leaving behind his wife who had suffered from ovarian cancer for 7 years, and his unattended 90-year-old mother. Similarly, Dr. Zhang, a 40-year-old urology doctor in an oncology hospital in Fudan University, Shanghai, ended his life by jumping from a building, due to a medical event. Doctors in many hospitals 
refuse to perform surgery in a metastatic tumor patient. After insisting and ensuring not to get the doctor in trouble, Dr. Zhang was moved by the plea of the patient and his family and went on to perform the risky operation. However, because of the poor prognosis the outcome was not well and the patient died in a short time. To Dr. Zhang's surprise, the patient's family became furious with him. They claimed that Dr. Zhang was responsible for the patient's death, and demanded compensation for the lost life by asking a great amount of money. After several months of being tracked, wrangled and threatened, Dr. Zhang fell ill to severe brain problems and pain. He had to seek help from a psychiatrist but unfortunately that did not help. A tragedy happened again. 'Another doctor left the world,' people sadly sighed.

To reduce the suicide rate, 1) the Chinese government should improve the policy of restricting doctors' work-hour. Overworked individuals should be able to consult a specialist without fearing the opinions of family, coworkers, and friends; 2) the department supervisors should study the experienced Suicide Prevention and Depression Awareness Program in 2009 launched by USAF [21]. In the suggested model, the strategy included educational outreach to destigmatize depression and remove roadblocks to treatment, web-based screening, in-person assessment, and referrals. Medical students should also be educated on the risk factors and recognize warning signs of burnout and depression and be equipped with setback and failure-resistance strategies; 3) harmonious and friendly relations between doctors and patients should be built as described in our previous study [10].
There are several limitations we can acknowledge in this review. First, the number of physicians' suicide is not accurate, as all recorded suicides were collected from websites or media. Some suicides may be underreported. Second, we are not completely sure whether part of suicides is due to overwork or not. There is no actual reported information of an individual's suicide work-hour on the websites. Third, several suicide methods (5\%) were unknown, and we became informed of the death from websites or media reports.

In summary, physician suicide is rigorous in China, and the government and medical institutions should act to prevent or guide physicians to fight the difficulties they encounter. They should also provide more free space and spare time to Chinese doctors. In response to doctor suicide, the appropriate law should be formulated by the government to ensure physicians' benefits, and to create a harmonious social environment. If physicians themselves are not well, they cannot serve their patients well either.

\section{Acknowledgement}

This study was supported by a grant from Chinese Medical Association Medical Education Branch and China's Higher Education and Medical Education Committee (2016B-YD002), Shanghai Higher Education Academy (GJSL1604), the Key Specialized Construction Project in Medicine of Shanghai (ZK2015A15) and Construction of key Academic Groups in Nephrology in Pudong New Area (PWZxq2017-07). All authors have approved the final version of the manuscript and have agreed to submit it to this journal. Yang XH and Zhang $B L$ contributed equally to this paper. Authors have no conflicts of interest.

\section{References}

1. Gold KJ, Sen A, Schwenk TL: Details on suicide among US physicians: data from the National Violent Death Reporting System. General. Hospital. Psychiatry 35(1), 45 (2013).

2. Gong Y, Han T, Chen W, et al. Prevalence of Anxiety and Depressive Symptoms and Related Risk Factors among Physicians in China: A Cross-Sectional Study. Plos. One 9(7), e103242 (2014).

3. Gagné P, Moamai J, Bourget D. Psychopathology and Suicide among Quebec Physicians: A Nested Case Control Study. Depress. Res. Treat, 2011 (2), 936327 (2011).

4. Hawton K, Clements A, Sakarovitch C, et al. Suicide in doctors: a study of risk accord- ing to gender, seniority and specialty in medical practitioners in England and Wales, 1979-1995. J. Epidemiol Community. Health 55(5), 296-300 (2001).

5. Hawton K, Agerbo E, Simkin S, et al: Risk of suicide in medical and related occupational groups: A national study based on Danish case population-based registers. J. Affect. Disord 134(1-3), 320-326 2011.

6. Petersen MR, Burnett CA. The suicide mortality of working physicians and dentists. Occup. Med, 58(58), 25-29 (2008).

7. Schernhammer ES, Colditz GA. Suicide Rates Among Physicians: A Quantitative and Gender Assessment (Meta-Analysis). Am. J. Psychiatry 161(12), 2295-2302 2004.

8. Wang CW, Chan CLW, Yip PSF. Suicide rates in China from 2002 to 2011: an update. Soc. Psychiatry Psychiatr. Epidemiol, 49(6), 929941 (2014)

9. Shan HP, Yang $\mathrm{XH}$, Zhan $\mathrm{XL}$, et al. Overwork is a silent killer of Chinese doctors: a review of Karoshi in China 2013-2015. Public. Health, 147(1), 98 (2017).

10. Pan $Y$, Yang $X H$, He JP, et al. To be or not to be a doctor, that is the question: a review of serious incidents of violence against doctors in China from 2003-2013. J. Public. Health 23(2), 111-116 (2015).

11. Zhao L, Zhang XY, Bai GY, et al. Violence against doctors in China. Bmj, 345(9945), e5730 (2012).

12. Hikiji W, Fukunaga T. Suicide of physicians in the special wards of Tokyo Metropolitan 
area. J.Forensic. Leg. Med 22(1), 37-40 (2014).

13. Palharesalves HN, Palhares DM, Laranjeira R, et al. Suicide among physicians in the state of Sao Paulo, Brazil, across one decade. Revista. Brasileira. De. Psiquiatria, 37(2), 146 (2015).

14. Li X, Zhang X. Female doctors in China: challenges and hopes. Lancet 386(10002), 1441-1442 (2015).

15. Aasland OG, Ekeberg O, Schweder T. Suicide rates from 1960 to 1989 in Norwegian physicians compared with other educational groups. Soc. Sci. Med 52(2), 259-265 (2001).
16. Kõlves K, De LD. Suicide in medical doctors and nurses: an analysis of the queensland suicide register. J. Nerv. Ment. Dis 201(11), 987-990 (2013).

17. Pan YJ, Lee MB, Lin CS. Physician suicide in Taiwan, 2000-2008: preliminary findings. J. Formos. Med. Assoc 108(4), 328-332 (2009).

18. Hiyama T, Yoshihara M. New occupational threats to Japanese physicians: karoshi (death due to overwork) and karojisatsu (suicide due to overwork). Occup. Environ. Med 65(6), 428-429 (2008).

19. Sasao S, Hiyama T, Tanaka S, et al. Medical malpractice litigation in gastroenterological practice in Japan: a 22-yr review of civil court cases. Am J Gastroenterol, 101(9),1951-1953 (2006).

20. Genovese JM, Berek JS. Can Arts and Communication Programs Improve Physician Wellness and Mitigate Physician Suicide? J. of Clinical Oncology, 34(15), (2016).

21. Moutier C, Norcross W, Jong P, et al. The suicide prevention and depression awareness program at the University of California, San Diego School of Medicine. Academic. Medicine, 87(3), 320 (2012). 